\title{
GPS Measurements of Present day crustal deformation within the Lebanese Restraining Bend along the Dead Sea Transform
}

\author{
Rani Jaafar \\ Dr. Francisco Gomez, Thesis Supervisor
}

\begin{abstract}
The Lebanese restraining bend is a $200 \mathrm{~km}$ long bend with a left lateral sense of slip located along the Dead Sea fault system (DSFS) between 33.2 and 34.6 degrees north latitude. The DSFS is a transform plate boundary fault system accommodating the differential northward movement of Arabian and Sinai plates relative to the Eurasian plate. Within the Lebanese Restraining bend, The DSFS splays into five left-lateral strike-slip faults, forming a positive flower structure. This study combines GPS measurements from Lebanon, where surveys span about 5.5 years, with sites from the Anti Lebanon Mountains in SW Syria for a more complete view of crustal deformation in the restraining bend. The GPS network includes continuous GPS sites and 27 campaign sites: 14 sites in Lebanon installed in 2002, 8 sites in Lebanon installed in 2005, and 5 sites in southwestern Syria. Preliminary velocities for older campaign sites have uncertainties less than $0.75 \mathrm{~mm} / \mathrm{yr}$, whereas newer sites have around $1.5 \mathrm{~mm} / \mathrm{yr}$ uncertainties. The improved spatial coverage and reduced uncertainties allow constructing; 1) elastic fault models that explore strain partitioning between two strike slip faults (Yammouneh and Serghaya faults) and a generalized off-shore thrust fault to accommodate convergence in the restraining bend, and 2) continuum (velocity gradient)
\end{abstract}


models that explore infinitesimal strain and rotation rates. The models suggest a displacement rate of 4.5-5.5 mm/yr along the Yammouneh fault and a counter clock wise rotation of $0.5^{\circ}-1.75^{\circ} / \mathrm{MA}$ within the bend. This study provides an essential tool for assessing the seismic hazard in the vicinity of the Lebanese restraining bend. 